\title{
Great Efficiency of Nucleosides as Organizing Tools
}

\author{
Sonja Merkaš, ${ }^{1,2}$ Souhaila Bouatra, ${ }^{1}$ Régis Rein, ${ }^{1}$ Ivo Piantanida, ${ }^{2}$ Mladen Žinić, ${ }^{2}$ Nathalie Solladié ${ }^{1, *}$
}

\footnotetext{
1 CNRS, 205 route de Narbonne, 31077 Toulouse, France; Université de Toulouse, UPS, INPT, 31077 Toulouse, France

2 Laboratory of Supramolecular and Nucleoside Chemistry, Ruđer Bošković Institute, Bijenička c. 54, HR-10000 Zagreb, Croatia

* Corresponding author's e-mail address: nathalie.solladie@Icc-toulouse.fr
}

RECEIVED: November 23, 2017 * REVISED: February 20, 2018 * ACCEPTED: March 26, 2018

THIS PAPER IS DEDICATED TO PROF. MLADEN ŽINIĆ ON THE OCCASION OF HIS 70 ${ }^{\text {Th }}$ BIRTHDAY

Abstract: Bis-porphyrins with flexible linkers such as uridine or 2'-deoxyuridin pre-organize in a face-to-face conformation and form stable sandwich complexes with bidentate base such as DABCO. The gain in stability can be even greater when a dinucleotide linker is used. Such preorganization increases the association constant by one to two orders of magnitude when compared to the one of DABCO with a reference porphyrin. Comparison with rigid tweezers shows a better efficiency of nucleosidic dimers. The choice of rigid spacers is not the only way to pre-organize bis-porphyrins, and well-chosen nucleosidic linkers offer an interesting option for the synthesis of such devices.

Keywords: porphyrins, tweezers, nucleosides, molecular recognition.

\section{INTRODUCTION}

E LABORATION of non-covalent multiporphyrinic assemblies represents an important challenge in relation to the mimicry of bacterial photosynthesis[1] and the design of functional molecular materials. ${ }^{[2]}$ Axial coordination to the central metal ions of porphyrins by suitable ligands is an effective and widespread strategy for the assembly of non-covalently bound multi-component systems. $\mathrm{Zn}(\mathrm{II})$ derivatives ${ }^{[3-4]}$ have been extensively used for this purpose and can be found in the literature.

For the last few years, we have focused on cofacial bis-porphyrin tweezers by host/guest interactions and investigated the possibility to obtain self-coordinated molecular systems with predictable spectral and redox characteristics. We reported a few years ago the synthesis of a bis-porphyrinic tweezers bearing a tris-anthracenic spacers. ${ }^{[5]}$ Specifically, a tris-anthracene spacer was chosen in order to facilitate a cofacial orientation of the chromophores while allowing free rotation around the acetylene axis, thus adjusting the cavity to a large variety of guests. Indeed, this adjustable tweezers is able to complex both small and large bidentate bases, as well as photoactive guests such as bipyridyl-porphyrins. ${ }^{[6]}$
However, synthesis of rigid tweezers can be long and tedious, especially for the preparation of rigid linkers which may bring solubility and stability problems. As part of our research on arborescent multi-porphyrins with nucleosidic linkers, we noticed that nucleosides seem to generate blocked conformers bringing the porphyrins in a face-toface orientation. ${ }^{[7]}$ We thus focus on the study of three bisporphyrins bearing either uridine or 2'-deoxyuridine derivatives as spacers. ${ }^{[8]}$ They differ by the positions where the chromophores are attached, either on the ribose or on the nucleic base. We also report the binding studies of these three bis-porphyrinic nucleosides with a bidentate base, DABCO. In two out of three cases, the nucleoside seems to confer sufficient preorganization to the dimers to enhance the association constants, documenting the fact that rigid dimers are not necessary for preorganization, and opening up new routes to the faster synthesis of flexible tweezers capable of complexing guests with a high association constant.

Furthermore, we recently highlighted that the gain in stability and the enhancement of the association constants for the complexation of bidentate base such as $\mathrm{DABCO}$ can be even greater when a dinucleotide linker is used. Such pre-organization increases the association 
constants by one to two orders of magnitude when compared to the association constants of the same bidentate ligands with a reference $\mathrm{Zn}(\mathrm{II})$ porphyrin.

\section{RESULTS AND DISCUSSION}

\section{Bis-Porphyrinic Tweezers with a Simple Nucleosidic Linker}

As part of our studies concerning complexation of bidentate Lewis bases by bis-porphyrinic tweezers, we synthesized a few years ago three new bis-porphyrins bearing a flexible nucleosidic linker (1, 2 and $\mathbf{3}$ in Figure 1$)$. These dimers differ by the attachment positions of the two porphyrins. For bis-porphyrinic dimers 1 and 2, both porphyrins are attached to the ribose, in the $0-2^{\prime}$ and $0-3^{\prime}$ positions of uridine for dimer 1 and in the $0-3^{\prime}$ and $0-5^{\prime}$ positions of $2^{\prime}$-deoxyuridine for dimer 2. ${ }^{[11]}$ For dimer $\mathbf{2}$ and 3, the anchoring position of one $\mathrm{Zn}$ (II) porphyrin at the $0-3^{\prime}$ position of the sugar moiety is conserved, while the second chromophore is attached either at the $0-5^{\prime}$ position of the $\mathbf{2}^{\prime}$-deoxyuridine for dimer $\mathbf{2}$ or at the C-5 position of the nucleic base for dimer 3 .

The synthesis of dimers $\mathbf{1}, \mathbf{2}$ and $\mathbf{3}$ has already been described. ${ }^{[8,9]}$ The ability of tweezers $\mathbf{1}, \mathbf{2}$ and $\mathbf{3}$ to accommodate guests of various size was investigated through binding studies carried out in dichloromethane with DABCO or 4,4'-bipyridine as bidentate bases. The complexations were monitored by UV-visible spectrophotometric titration of a solution of tweezers in $\mathrm{CH}_{2} \mathrm{Cl}_{2}\left([\mathbf{1}]=2.7 \times 10^{-5} \mathrm{M}\right.$, [2] = $\left.3.0 \times 10^{-5} \mathrm{M},[3]=2.4 \times 10^{-5} \mathrm{M}\right)$, which resulted as expected in a significant red-shift of the Soret and $Q$ bands in the porphyrin (Figure 2). ${ }^{[10]}$
The association constants for the formation of the complexes were calculated from UV-visible spectroscopic data. A value of $2.5 \times 10^{4} \mathrm{M}^{-1}$ was found for tweezers 1 , which is similar to the association constant of DABCO with a reference $\mathrm{Zn}$ (II) porphyrin 5,10,15,20-tetra-di-tert-butylphenyl-porphyrin $\mathrm{A}_{4}\left(2.5 \times 10^{4} \mathrm{M}^{-1}\right)$, thus indicating as expected that no well-defined pre-organized conformation exists for bis-porphyrin 1. However, much higher binding constants were found for the formation of host/guest complexes between tweezers $\mathbf{2}$ and $\mathbf{3}$ and DABCO. Values of $6.3 \times 10^{5} \mathrm{M}^{-1}$ and $2.0 \times 10^{6} \mathrm{M}^{-1}$ were found. These association constants are increased by 1.5 or 2 orders of magnitude as compared to the association constants of the same bidentate ligand with the above cited reference $\mathrm{Zn}$ (II)

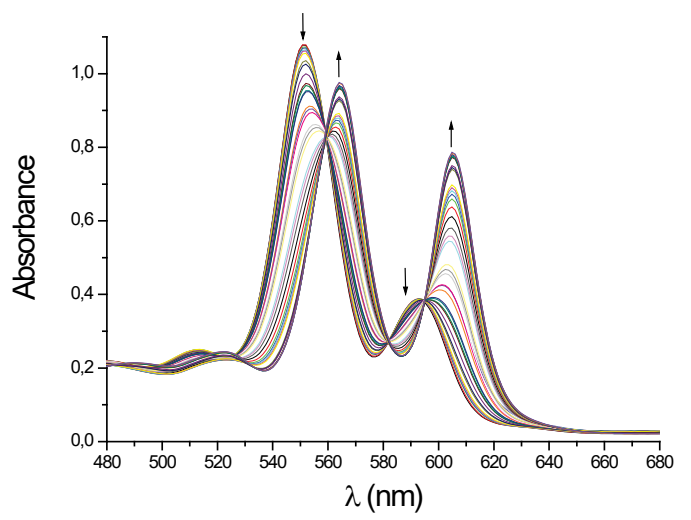

Figure 2. UV-Vis spectroscopic titration of dimer 2 with DABCO in $\mathrm{CH}_{2} \mathrm{Cl}_{2}$ at rt. Spectral changes of 2 on addition of $\mathrm{DABCO}$ at rt: $[2]=3.10^{-5} \mathrm{M}$, concentration ratio [DABCO $\left./ / 2\right]=$ 0 to 100

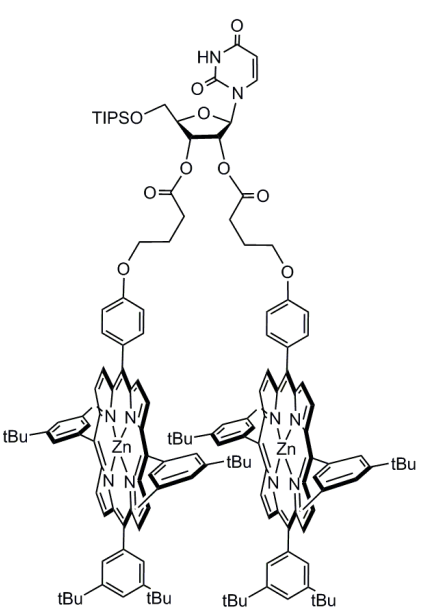

1

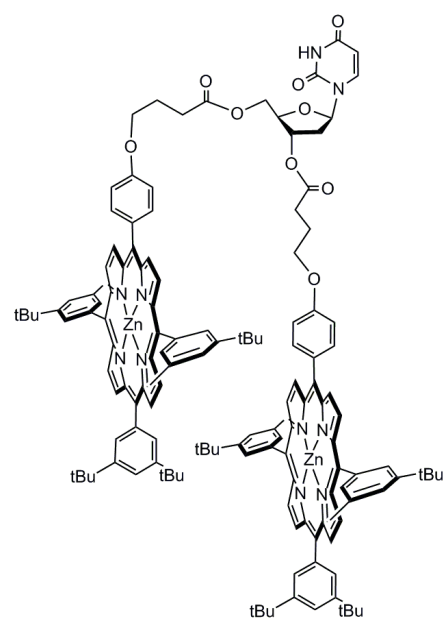

2

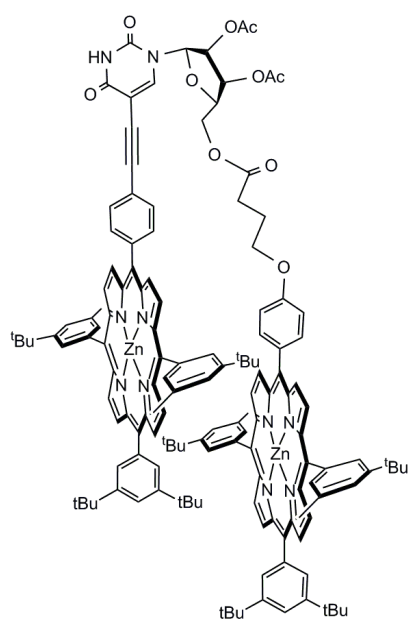

3

Figure 1. Three new bis-porphyrins bearing a flexible nucleosidic linker and differing by the attachment positions of the two porphyrins. 
porphyrin. This enhanced stability of the complex may be ascribed to a pre-organization of the bis-porphyrinic tweezers $\mathbf{2}$ and $\mathbf{3}$ forming a cavity and provides convincing evidence that the bidentate base is inserted into the cavity of both dimers via host/guest interactions. Such results were expected for tweezers $\mathbf{3}$ since it is known that the anti-conformation is blocked for uridine in the presence of bulky substituents on the nucleic base, providing more favorable conditions for the second porphyrin to come in a face-to-face orientation. However, no explanation could be found to explain such a high complexing capability of tweezers 2.

The adjustment of the cavity to bidentate guests of various size was investigated for tweezers $\mathbf{2}$ and $\mathbf{3}$ through binding studies realized in dichloromethane between these dimers and 4,4'-bipyridine. The complexations were monitored by UV-visible spectrophotometric titration of a solution of tweezers in $\mathrm{CH}_{2} \mathrm{Cl}_{2}\left([2]=2.9 \times 10^{-5} \mathrm{M}\right.$, [3] = $\left.2.2 \times 10^{-5} \mathrm{M}\right)$, which resulted as expected in a significant red-shift of the Soret and $Q$ bands in the porphyrin. ${ }^{[10]}$ The association constants for the formation of the complexes were calculated from UV-visible spectroscopic data. Values of $1.3 \times 10^{5} \mathrm{M}^{-1}$ and $3.2 \times 10^{5} \mathrm{M}^{-1}$ were found for tweezers 2 and 3 respectively. These binding constants are increased by 1 or 1.5 order of magnitude as compared to the association constants of the same bidentate ligand with a reference $\mathrm{Zn}$ (II) porphyrin 5,10,15,20-tetra-di-tert-butylphenyl-porphyrin $\mathrm{A}_{4}\left(7.9 \times 10^{3} \mathrm{M}^{-1}\right)$, indicating an enhanced stability of the complex, which may be ascribed to a preorganization of the bis-porphyrinic tweezers $\mathbf{2}$ and $\mathbf{3}$ forming a cavity. These results document the insertion of the bidentate base into the cavity of the dimers via host/guest interactions, and clearly demonstrate the adjustment of the cavity to the size of the complexed guest.

\section{Rigid Cofacial Bis-Porphyrinic Tweezers}

To rationalize the pre-organization of these flexible dimers and their capability to behave as tweezers to complex bidentate guests, it is interesting to compare the obtained results with those of a rigid cofacial bis-porphyrinic tweezers 4 we synthesized. ${ }^{[5]}$ More specifically, this rigid dimer was designed in order to force the cofacial orientation of the porphyrins to create a cavity between the two chromophores, thus making them capable of hosting bidentate guests of appropriate size. Poly-anthracenes were chosen as rigid spacer for the construction of this tweezers. The tris-anthracenic spacer used in $\mathbf{4}$ forces a cofacial orientation of the chromophores while allowing a free rotation around the acetylenic axis, thus adjusting the cavity size to accommodate a large variety of guests (Figure 3 ).

The ability of $\mathbf{4}$ to accommodate various guests was investigated through binding studies carried out in dichloromethane with two bidentate bases of different

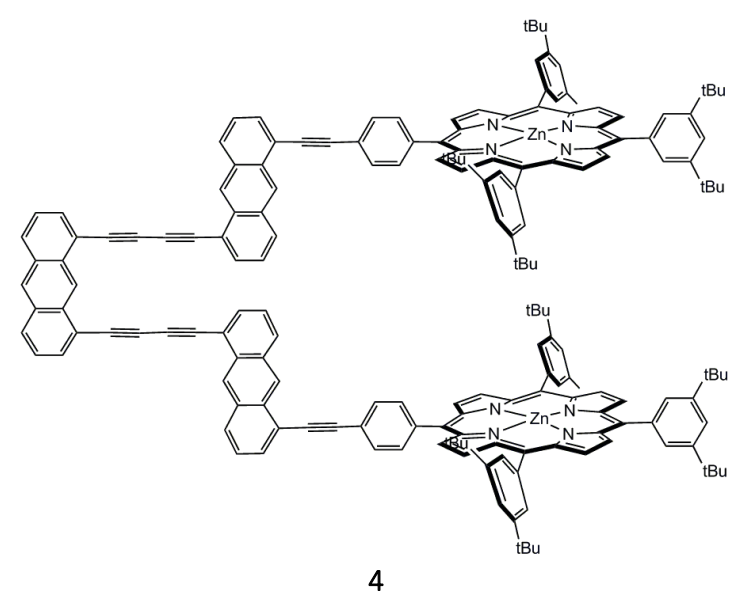

Figure 3. Rigid cofacial bis-porphrynic tweezers with trisanthracenic spacer 4 .

lengths and pKa values, namely DABCO and 4,4'bipyridine. ${ }^{[5]}$ In particular, the complexations were monitored by a UV-visible spectrophotometric titration in $\mathrm{CH}_{2} \mathrm{Cl}_{2}$. The association constants $\left(K_{\mathrm{a}}\right)$ between tweezers 4 and both bases were calculated from the UV-visible spectroscopic data and values of $3.9 \times 10^{5} \mathrm{M}^{-1}$ and $4.0 \times 10^{4} \mathrm{M}^{-1}$ were found for $D A B C O$ and $4,4^{\prime}$-bipyridine respectively. These association constants are increased by one order of magnitude, when compared to the association constant for the binding of the same bidentate ligands with a reference $\mathrm{Zn}$ (II) porphyrin 5,10,15,20-tetra-di-tert-butyl-phenyl-porphyrin $\mathrm{A}_{4}\left(2.5 \times 10^{4} \mathrm{M}^{-1}\right.$ for DABCO and $4.0 \times 10^{3} \mathrm{M}^{-1}$ for $4,4^{\prime}$-bipyridine), in spite of the difference in sizes of the guests involved in this recognition process ( $2.7 \AA$ and $7.1 \AA$ respectively) and of the cavity of dimer 4 in its extended conformation ( $c a .15 \AA$ ). The enhanced stability of the complex is ascribed to the pre-organization of the bis-porphyrinic tweezers 4 . These results provide convincing evidence of the adjustability of the host's cavity size to fit the guest to be accommodated.

\section{Rigid or Flexible Bis-Porphyrinic Tweezers?}

Molecular modeling studies of $\mathbf{4 , 2}$ and $\mathbf{3}$ and their $1 / 1$ complexes with DABCO were carried out by geometry optimizations using molecular mechanics with the ESFF force field and are represented in Figure 4 . In the absence of guest, the center to center distance between the two Zn(II) porphyrins are $15 \AA, 6.7 \AA$ and $10.4 \AA$ respectively for dimers $\mathbf{4}, \mathbf{2}$ and $\mathbf{3}$. The insertion of DABCO into the cavity results in a distortion of the molecule, which adopts a conformation with a center to center distance between the chromophores of $7.4 \AA$. However, as mentioned above, one to two orders of magnitude are gained in the association constant documenting the fact that the cavity is 
flexible enough to adapt to the complexed guest without gaining too much tension energy likely to distabilize the complex. The cavity of dimers $\mathbf{4}$ and $\mathbf{3}$ is reduced by $7.6 \AA$ and $3 \AA$ respectively when forming the complexes, while the cavity of tweezers 3 expands by $0.7 \AA$ upon complexation of DABCO.

\section{Dinucleotide: Particularly High Association Constant for the Formation of a Sandwich Type Molecular Complex}

We recently synthesized bis-porphyrinic dimer 5 based on a di-nulceosidic linker (Figure 5) and studied its complexation capabilities by UV-Vis spectroscopy. The gain in stability for the formation of sandwich type host-guest complex with DABCO can be even greater when a dinucleotide linker is used. Such pre-organization increases the association constants by one to two orders of magnitude when compared to the association constants of the same bidentate ligands with a reference $\mathrm{Zn}$ (II) porphyrin. Comparison of these results with those obtained for rigid tweezers 4 shows a better efficiency of the flexible nucleosidic dimers.
The ability of di-nucleotide 5 to accommodate guests was investigated through binding studies carried out in dichloromethane with DABCO as bidentate base. As reported in some of our previous publications, ${ }^{[12]}$ it was assumed that the di-nucleosidic bis-porphyrin could be preorganized and thus facilitate the coordination of this rigid bifunctional ligand. The synthesized molecular system is amenable to preorganization, because its architecture is based on combination of rigid and flexible linkers. The architecture of multi-porphyrinic systems is important because the covalent connectivity between the interacting centers commands the geometry of resulting assembly and the relative orientation of chromophores dictates the strength of the interaction with ligands. As already noted, the geometry of porphyrins in supramolecular assembly is crucial in design of artificial light-harvesting complexes. ${ }^{[11-29]}$ Data obtained by UV-visible titrations were analyzed by using the values of the absorbance at fixed wavelengths, which method is exclusively valid for the complexes with stoichiometry $1 / 1$, and by simultaneous fitting of the whole series of spectra collected at $1 \mathrm{~nm}$ intervals using the software SPECFIT. ${ }^{[30-34]}$
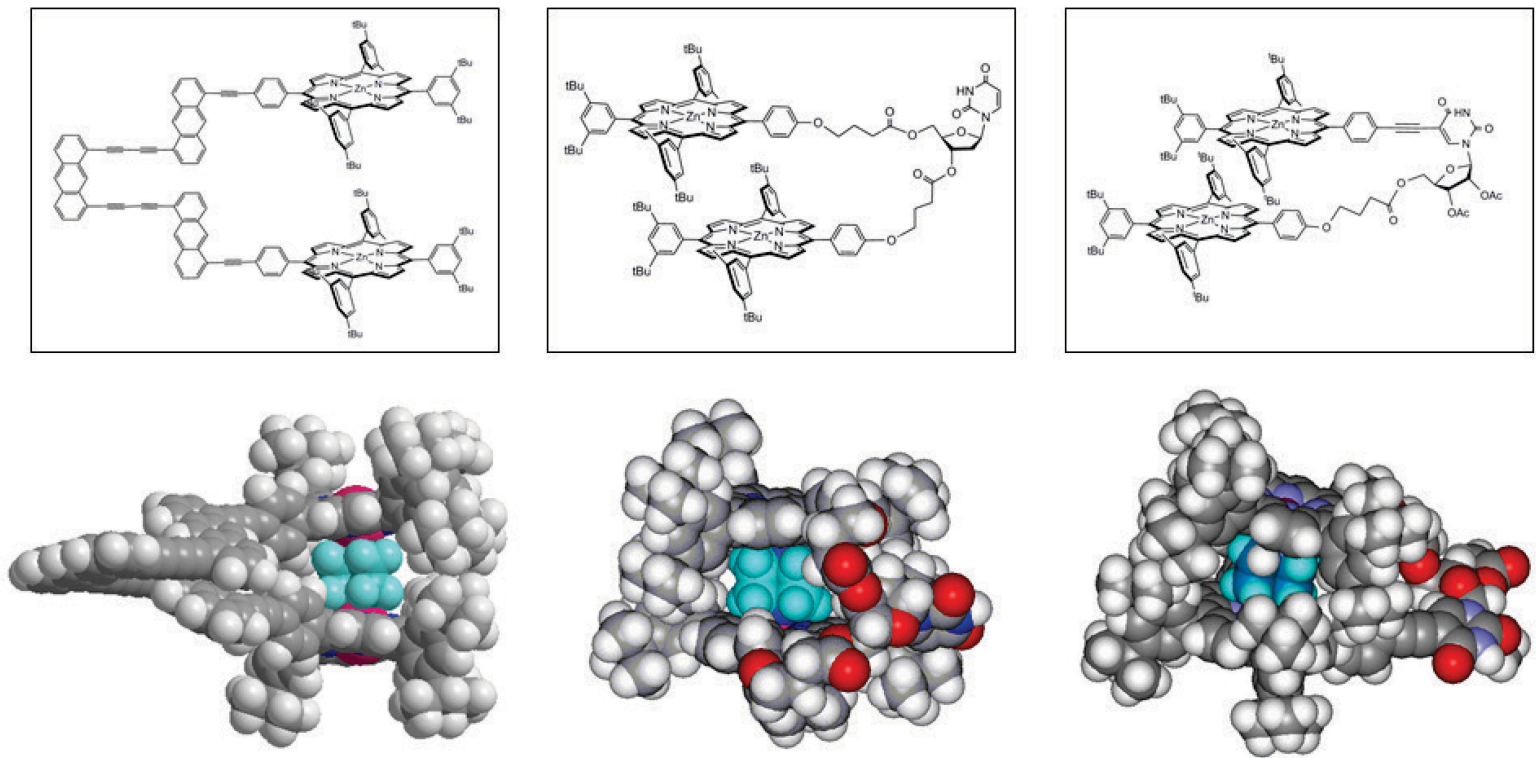

4/DABCO

2/DABCO

$$
\mathrm{d}_{\mathrm{Zn}-\mathrm{Zn}}=7.3 \AA
$$

Tweezers:

$$
\log \mathrm{K}_{\mathrm{ass}}=5.6
$$

Mono-Porph:

$$
\mathrm{d}_{\mathrm{Zn}-\mathrm{Zn}}=7.4 \AA
$$$$
\log \mathrm{K}_{\mathrm{ass}}=5.8
$$

$\log K_{\text {ass }}=4.4$

\section{3/DABCO}

$\mathrm{d}_{\mathrm{Zn}-\mathrm{Zn}}=7.4 \AA$

$\log K_{\text {ass }}=6.3$

$\log \mathrm{K}_{\mathrm{ass}}=4.4$

Figure 4. Molecular modeling of dimers 4, 2 and 3 and their 1/1 complexes: 4/DABCO, 2/ DABCO, 3/DABCO. The center to center distance between the two porphyrins is $\sim 7.4 \AA$ in all dimers. Geometry optimizations have been done by molecular mechanics with the ESFF force field using the computer program Spartan. 


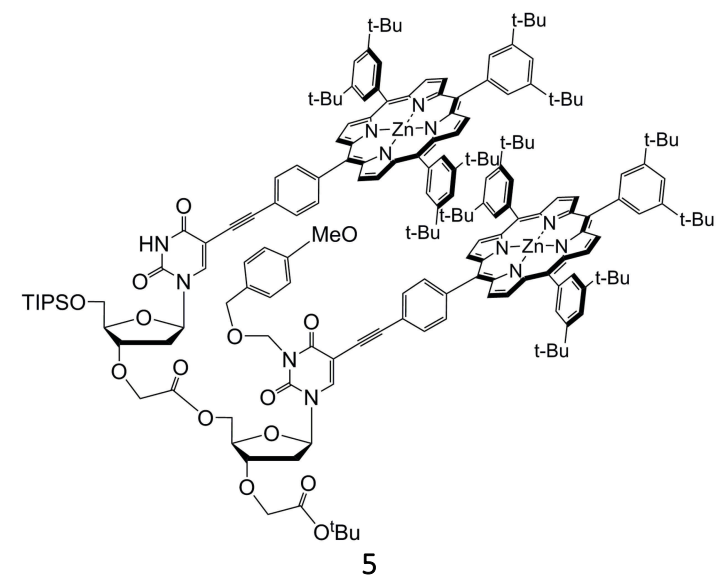

Figure 5. Rigid cofacial bis-porphrynic tweezers with trisanthracenic spacer 5 .

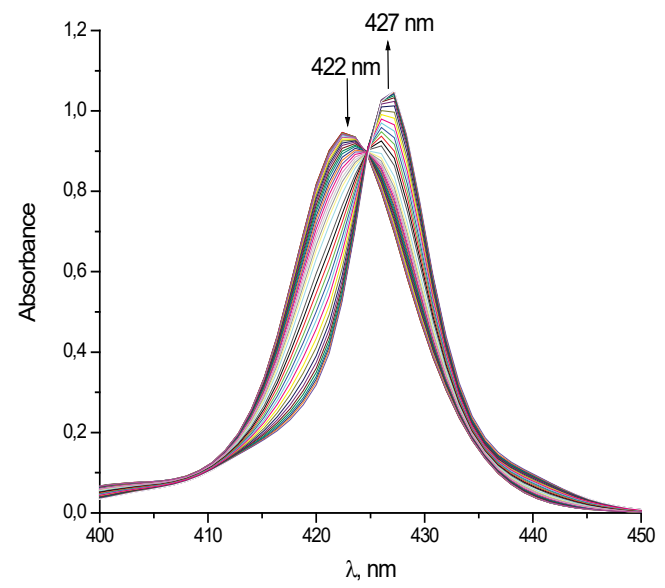

After examining the complexation of the simple porphyrin with DABCO, we studied the binding of the same base to dimer $\mathbf{5}$, the bis-porphyrinic tweezer appended to an appropriate position of the flexible uridinic scaffold by the rigid acetylene group. The titration of the dimer with DABCO was measured by using the coordination shift of the Soret absorption as well as the Q-bands. The Soret band absorption was measured at the concentration of $1.04 \times 10^{-6} \mathrm{M}$ which corresponds to an absorbance of 0.95 at $422 \mathrm{~nm}$. The titration was performed in two parts to be analyzed in terms of two-state equilibria. The first part of the titration was processed until 2 equivalents of DABCO were added per porphyrin. The complete titration that involved an addition of DABCO until 6000 equivalents per porphyrin was performed separately, Figure 6.

The clean isosbesticity of spectra obtained in the first part of the titration demonstrates that the only colored

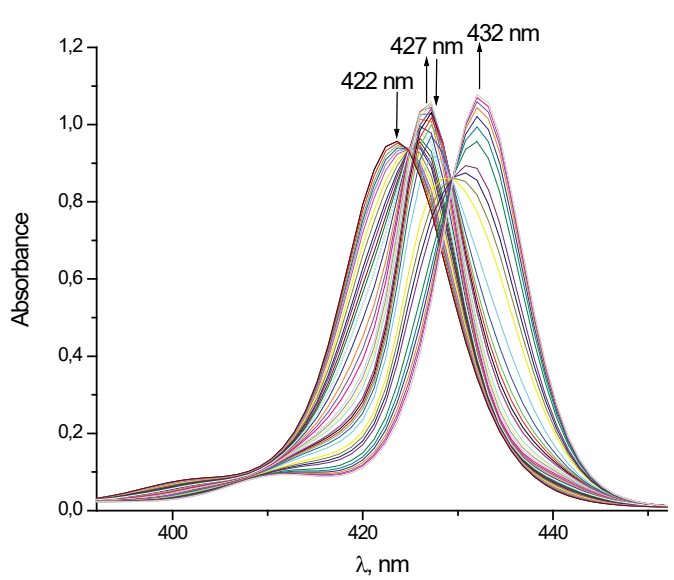

Figure 6. UV-visible titration of bis-porphyrinic tweezer 5 with $\mathrm{DABCO}$ in $\mathrm{CH}_{2} \mathrm{Cl}_{2}$ at rt. On the left hand side first part of the titration and on the right the complete titration.

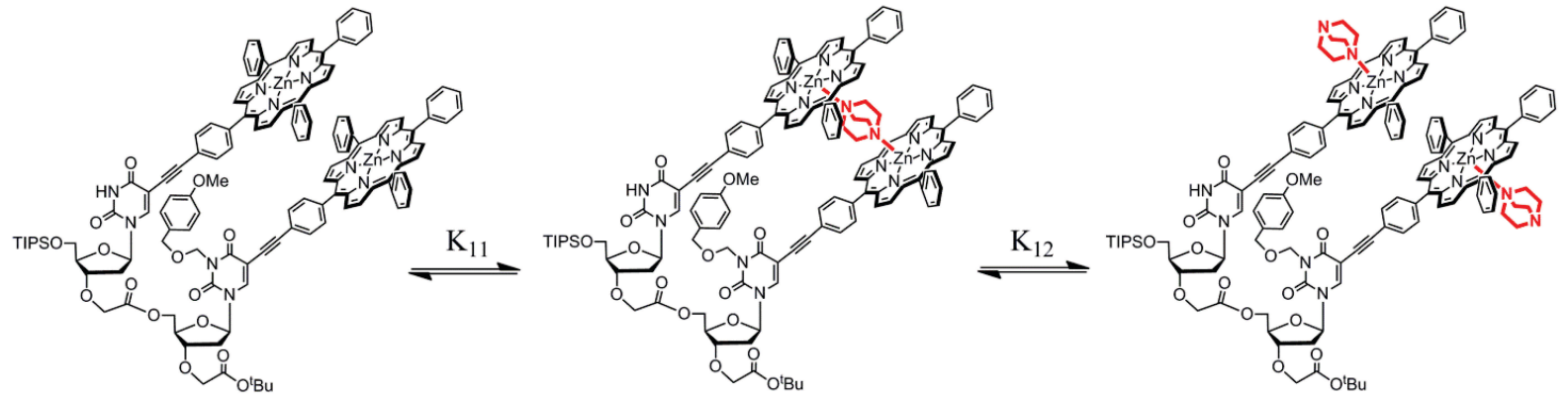

Figure 7. Representation of the proposed equilibria involved in the binding of DABCO to bis-porphyrinic tweezer 5 . For clarity reasons tert-butyls on meso-phenyls are omitted. 
species present in solution are free dimer $\mathbf{5}$ and one type of its complex with DABCO. The observed spectral changes are quite similar to those obtained in the titration of the monomer. However, there are some minor spectral changes, i.e. smaller red shift of the Soret peak, from 422 to $427 \mathrm{~nm}$, as well as intensified and sharpened form of the titration spectrum. A shift in the Soret band of $5 \mathrm{~nm}$ is exactly two times smaller than the shift obtained for the $1 / 1$ monomer/DABCO complex. Accordingly, it was reasonable to anticipate formation of the intramolecular $1 / 1$ sandwich complex. On addition of more DABCO, intensity of the absorption band at $427 \mathrm{~nm}$ decreased, and a new absorption band appeared at $432 \mathrm{~nm}$. As observed in the titration spectrum of the monomer, the Soret absorption at $432 \mathrm{~nm}$ is typical for the simple $1 / 1$ porphyrin/DABCO complex. On the basis of the changes in absorption spectra, the possible two consecutive two-state equilibria with corresponding stepwise constants in the binding of DABCO to bis-porphyrinic tweezer $\mathbf{5}$ are shown in Figure 7.

The first method for calculation of the binding constant by using titration data at selected wavelengths was applied only to the first part of the titration characterized by sharp isosbestic point. This analysis could be performed because the complexation by $1 / 1$ binding model was envisaged in the first equilibrium. The binding constant for the $1 / 1$ dimer/DABCO complex was found to be $7.4 \times 10^{6} \mathrm{M}^{-1}\left(\log K_{11}=6.9\right)$. The formation of this type of a complex was verified by analysis of the whole set of spectra which correspond to the first part of the titration by using SPECFIT. The analysis resulted with only one possible $1 / 1$ complex with corresponding binding constant $\log K_{11}=6.42 \pm 0.03$. It is interesting to note that calculated $\log K_{11}$ for $1 / 1$ dimer/DABCO complex is more than one order of magnitude higher than log $K_{11}$ for $1 / 1$ monomer/DABCO complex. Taken together, these results strongly support formation of $1 / 1$ dimer/DABCO sandwich complex through the chelate effect. The whole spectra obtained by the complete titration was analyzed in terms of three possible colored species: free dimer 5, 1/1 sandwich complex, and $1 / 2$ open complex (Figure 7). Fitting of the titration data revealed that $1 / 1$ and $1 / 2$ binding models for dimer/DABCO are only possible, Figure 8 .

Fitting to $1 / 1$ binding isotherm yielded the stoichiometric binding constant $\log K_{11}=6.65 \pm 0.08$, while the fit to $1 / 2$ binding model provided log $K_{12}=3.21 \pm 0.10$. The calculated log $K_{11}$ is almost identical to log $K_{11}$ value obtained in the analysis of the first part of the titration.
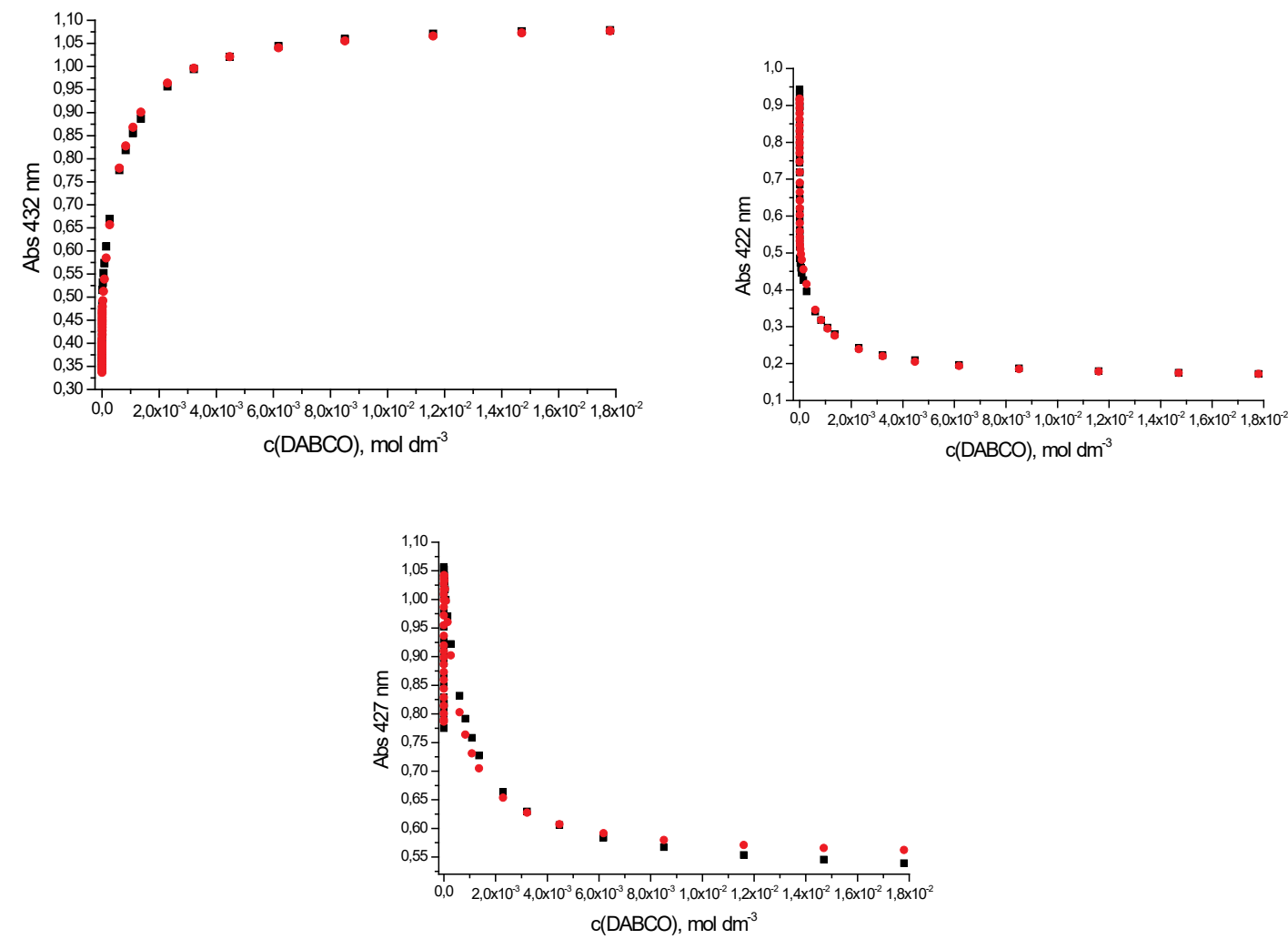

Figure 8. UV-visible titration data (change in absorbance at three wavelengths, 422,427 and $432 \mathrm{~nm}$ ) for the binding of bisporphyrinic tweezer 5 with DABCO, fitted to the calculated curves for the equilibria in Figure 7. 
Moreover, calculated log $K_{12}$ value is three orders of magnitude lower than log $K_{11}$ value. Therefore, dissociation of the more stable chelated $1 / 1$ complex is followed by coordination of second DABCO and by that formation of the $1 / 2$ complex in which two DABCO molecules are coordinated to two porphyrins of the dimer. Both, $1 / 1$ and $1 / 2$ complexes involved in these consecutive two-state equilibria are in agreement with the species represented in Figure 7.

Similar formation of sandwich complexes was evidenced by Sanders, Hunter, Anderson and coworkers. ${ }^{[35-41]}$ These studies show that sandwich complex formation is in concert with the parallel orientation of two porphyrin macrocycles. In this respect, the shifts in titration spectra are caused by proximity of the porphyrins and in this line increased interporphyrinic electronic interaction. The Soret band of the free dimer 5 has fwhm $15 \mathrm{~nm}$, and the Soret band of the dimer/DABCO sandwich complex $11 \mathrm{~nm}$. It is believed that this narrowing indicate a significant increase in the center-to-center distance between the two porphyrins, due to the insertion of DABCO into the bis-porphyrinic cavity. This hypothesis is in great agreement with the half width at half maximum of $13 \mathrm{~nm}$ for the $1 / 2$ dimer DABCO open complex. The outer coordination of DABCO allows a shorter center-to-center distance between the porphyrins.

These results thus document the fact that the choice of rigid spacers is not the only way to pre-organize bisporphyrins, and that some well-chosen nucleosidic linkers offer an interesting option for the synthesis of such devices. Furthermore, the chirality and enantio-purity of the nucleosidic linkers paves the way toward the selective complexation of enantio-pure bidentate guests and the resolution of racemates.

\section{SUMMARY}

We report herein that flexible linkers such as uridine or 2'deoxyuridine generate blocked conformers bringing the two porphyrins in a face-to-face position. Bis-porphyrins with flexible linkers such as uridine or 2'-deoxyuridin preorganize in a face-to-face conformation and form stable sandwich complexes with bidentate base such as DABCO. The gain in stability can be even greater when a dinucleotide linker is used. Such pre-organization increases the association constants by one to two orders of magnitude when compared to the association constants of the same bidentate ligands with a reference $\mathrm{Zn}$ (II) porphyrin. Comparison of these results with those obtained for rigid tweezers $\mathbf{4}$ shows a better efficiency of the flexible nucleosidic dimers. We thus document the fact that the choice of rigid spacers is not the only way to pre-organize bis-porphyrins, and that some well-chosen nucleosidic linkers offer an interesting option for the synthesis of such devices. Furthermore, achiral bis-porphyrinic tweezers have already been used for supramolecular chirogenesis. The bulkiness of chiral ligands plays an important role in supramolecular chirality induction by controlling conformational changes in achiral hosts via steric repulsion, with larger ligands inducing more intense CD signals. ${ }^{[42]}$ For these reasons, we believe that the chirality and enantiopurity of the nucleosidic linkers of our tweezers could pave the way toward the selective complexation of enantio-pure bidentate guests and the resolution of racemates.

Acknowledgment. This work was supported by the CNRS and the French Ministry of Research. We also thank the French Government for a grant to Sonja Merkas for her PhD.

\section{REFERENCES}

[1] a) O. Shoji, S. Okada, A. Satake, Y. Kobuke, J. Am. Chem. Soc. 2005, 127, 2201; b) R. Takahashi, Y. Kobuke, J. Am. Chem. Soc. 2003, 125, 2372; c) Y. Kuroda, K. Sugou, K. Sasaki, J. Am. Chem. Soc. 2000, 122, 7833; d) R. A. Haycock, A. Yartsev, U. Michelsen, V. Sundström, C. A. Hunter, Angew. Chem. Int. Ed. 2000, 39, 3616; e) T. Hayashi, H. Ogoshi, Chem. Soc. Rev. 1997, 26, 355.

[2] a) H. L. Anderson, Chem. Commun. 1999, 0, 2323; b) C. M. Drain, J. T. Hupp, K. S. Suslick, M. R. Wasielewski, X. Chen, J. Porphyrins Phthalocyanines 2002, 6, 243.

[3] a) Y. Kuramochi, A. S. D. Sandanayaka, A. Satake, Y. Araki, K. Ogawa, O. Ito, Y. Kobuke, Chem. Eur. J. 2009, 15, 2317; b) Y. Kuramochi, Y. Kawakami, A. Satake, Inorg. Chem. 2017, 56, 11008.

[4] a) C. Roche, Q. Luo, G. Gil-Ramirez, H. W. Jiang, D. R. Kohn, Y. Xiong, A. L. Thompson, H. L. Anderson, J. Org. Chem. 2017, 82, 7446; b) M. Rickhaus, J. A. Vargas, L. Tejerina, I. Grubner, M. Jirasek, T. D. W. Claridge, H. L. Anderson, J. Am. Chem. Soc. 2017, 139, 16502; c) S. Brittle, T. H. Richardson, A. D. F. Dunbar, S. Turega, C. A. Hunter, J. Phys. Chem. B. 2008, 112, 11278; d) C. A. Hunter, C. M. R. Low, M. J. Packer, S. E. Spey, J. G. Vinter, M. O. Vysotsky, C. Zonta, Angew. Chem. Int. Ed. Engl. 2001, 40, 2678; e) K. Ogawa, Y. Kobuke, Angew. Chem . Int. Ed. Engl. 2000, 39, 4070.

[5] R. Rein, M. Gross, N. Solladié, Chem. Commun. 2004, O, 1992.

[6] L. Flamigni, A. M. Talarico, B. Ventura, R. Rein, N. Solladié, Chemistry A Eur. J. 2006, 12, 701.

[7] L. Flamigni, A. M. Talarico, B. Ventura, G. Marconi, C. Sooambar, N. Solladié, Eur. J. Inorg. Chem. 2004, 2557. 
[8] N. Solladié, S. Bouatra, S. Merkas, R. Rein, R. Roeser J. Porphyrins Phtalocyanines 2005, 9, 779.

[9] N. Solladié, F. Aziat, S. Bouatra, R. Rein, J. Porphyrins Phtalocyanines 2008, 12, 1250.

[10] a) C. A. Hunter, L. D: Sarson, Angew. Chem. Int. Ed. Engl. 1994, 33, 2313; b) X. Chi, A. Guerin, J. R. A. Haycock, C. A. Hunter, L. D. Sarson, J. Chem. Soc. Chem. Commun. 1995, 2567; c) C. A. Hunter, R. K. Hyde, Angew. Chem. Int. Ed. Engl. 1996, 35, 1936; d) C. A. Hunter, R. J. Shannon, J. Chem. Soc. Chem. Commun. 1996, 11, 1361; e) C. C. Mak, N. Bampos, J. M. K. Sanders, Angew. Chem. Int. Ed. Engl. 1998, 37 , 3020; f) N. Armaroli, F. Diederich, L. Echegoyen, T. Habicher, L. Flamigni, G. Marconi, J.-F. Nierengarten, New J. Chem. 1999, 23, 77.

[11] S. Fukuzumi, K. Saito, K. Ohkubo, V. Troiani, H. Qiu, S. Gadde, F. D'Souza, N. Solladié, Phys. Chem. Chem. Phys. 2011, 13, 17019.

[12] J. J. Piet, P. N. Taylor, H. L. Anderson, A. Osuka, J. M. Warman, J. Am. Chem. Soc. 2000, 122, 1749.

[13] A. Satake, Y. Kobuke, Tetrahedron 2005, 61, 13.

[14] M. Choi, T. Yamazaki, I. Yamazaki, T. Aida, Angew. Chem. Int. Ed. 2004, 43, 150.

[15] K. Tomizaki, L. Yu, L. Wei, D. F. Bocian, J. S. Lindsey, J. Org. Chem. 2003, 68, 8199.

[16] I. W. Hwang, T. Kamada, T. K. Ahn, D. M. Ko, T. Nakamura, A. Tsuda, A. Osuka, D. Kim, J. Am. Chem. Soc. 2004, 126, 16187.

[17] C. C.Mak, N. Bampos, S. L. Darling, M. Montalti, L. Prodi, J. K. M. Sanders, J. Org. Chem. 2001, 66, 4476.

[18] R. A. Haycock, A. Yartsev, U. Michelsen, V. Sundström, C. A. Hunter, Angew. Chem. Int. Ed. 2000, 39, 3616.

[19] J. Bretar, J.-P. Gieselbrecht, M. Gross, N. Solladié, Chem. Commun. 2001, 733.

[20] R. Rein, M. Gross, N. Solladié, Chem. Commun. 2004, 1992.

[21] L. Flamigni, A. M. Talarico, B. Ventura, R. Rein, N. Solladié, Chem. Eur. J. 2006, 12, 701.

[22] C. Ikeda, Y. Tanaka, T. Fujihara, Y, Ishii, T. Ushiyama, K. Yamamoto, N. Yoshioka, H. Inoue, Inorg. Chem. 2001, 40, 3395.

[23] C. Ikeda, A. Satake, Y. Kobuke, Org. Lett. 2003, 5, 4935.
[24] K. Kameyama, A. Satake, Y. Kobuke, Tetrahedon Lett. 2004, 45, 7617.

[25] M. Schmittel, R. S. K. Kishore, Org. Lett. 2004, 6, 1923.

[26] T. S. Balaban, R. Goddard, M. Linke-Schaetzel, J.-M. Lehn, J. Am. Chem. Soc. 2003, 125, 4233.

[27] E. lengo, E. Zangrando, E. Alessio, Eur. J. Inorg. Chem. 2003, 13, 2371.

[28] E. lengo, E. Zangrando, E. Alessio, J.-C. Chambron, V. Heitz, L. Flamigni, J.-P. Sauvage, Chem. Eur. J. 2003, 9, 5879.

[29] K. Sugou, K. Sasaki, K. Kitajima, T. Iwaki, Y. Kuroda, J. Am. Chem. Soc. 2002, 124, 1182.

[30] SPECFIT; Global Least Squares fitting by Factor Analysis and Marquart Minimization.

[31] H. Gampp, M. Maeder, C. J. Meyer, A. D. Zuberbühler, Talanta 1986, 33, 943.

[32] H. Gampp, M. Maeder, C. J. Meyer, A. D. Zuberbühler, Talanta 1985, 32, 95.

[33] C. C. Mak, N. Bampos, J. K. M. Sanders, Angew. Chem. Int. Ed. 1998, 37, 3020.

[34] P. Ballester, A. Costa, A. M. Castilla, P. M. Deyà, A. Frontera, R. M. Gomila, C. A. Hunter, Chem. Eur. J. 2005, 11, 2196.

[35] C. A. Hunter, M. N. Meah, J. K. M. Sanders, J. Am. Chem. Soc. 1990, 112, 5773.

[36] H. L. Anderson, C. A. Hunter, M. N. Meah, J. K. M. Sanders, J. Am. Chem. Soc. 1990, 112, 5780.

[37] H. J. Kim, N. Bampos, J. K. M. Sanders, J. Am. Chem. Soc. 1999, 121, 8120.

[38] C. A. Hunter, R. Tregonning, Tetrahedron 2002, 58, 691.

[39] C.C. Mak, D. Pomeranc, M. Montelti, L. Prodi, J. K. M. Sanders, Chem. Commun. 1999, 1083.

[40] G. S. Wilson, H. L. Anderson, Chem. Commun. 1999, 16, 1539.

[41] L. Baldini, P. Ballester, A. Casnati, R. M. Gomila, C. A. Hunter, F. Sansone, R. Ungaro, J. Am. Chem. Soc. 2003, 125, 14181.

[42] a) V. V. Borovkov, Symmetry 2014, 6, 256; b) V. V. Borovkov, J. M. Lintuluoto, Y. Inoue, Org. Lett. 2000, 2,1565 ; c) X. Huang, B. Borhan, B. H. Rickman, K. Nakanishi, N. Berova, Chem. Eur. J. 2000, 6, 216. 